\section{New painting plant for coaches and city buses in Pune, India}

India is the second largest market for buses in the world, with 50,000 buses being purchased every year. Since 2008, Daimler has introduced two coach models there, together with a city bus in the first quarter of 2012. The chassis are supplied by Mercedes-Benz in Stuttgart. MCV India, its global bodybuilding partner, assembles and paints the bodies at the Mercedes-Benz India plant in Chakan, Pune. In order to meet the required high quality standards for the finish of the buses, MCV (Manufacturing Commercial Vehicles) once again chose a painting plant from Lutro consisting of three large spray booths to accommodate the planned volume of 900 buses per year in India. Lutro has supplied several painting plants to MCV facilities throughout the world over recent decades.

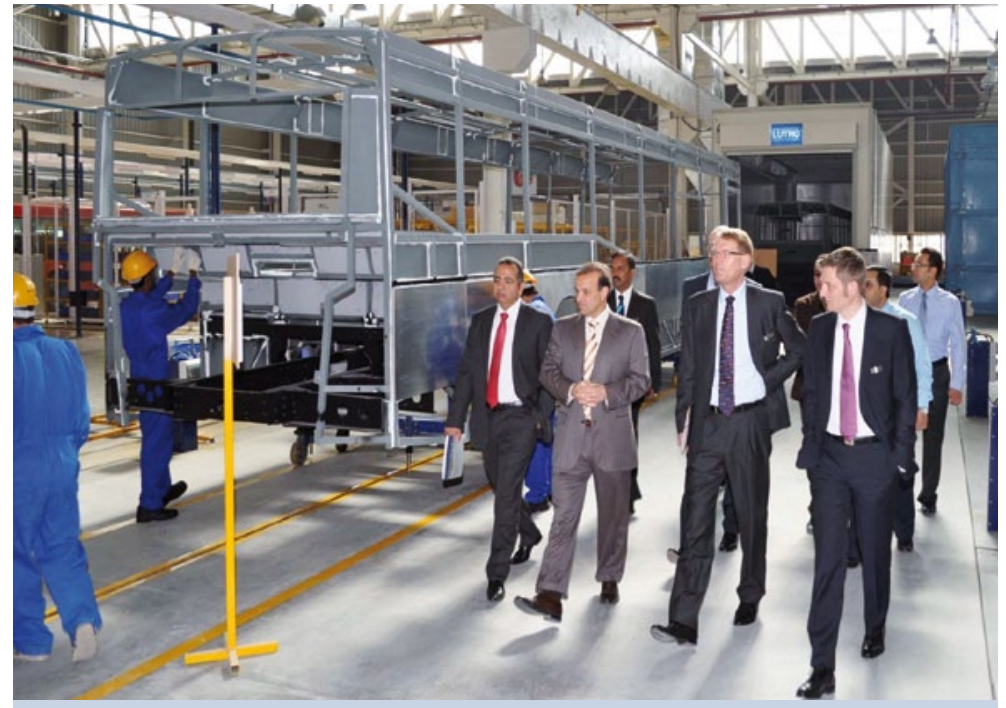

Eng. Karim Ghabbour (second from left), owner of MCV, and Hartmut Schick (second from right), head of the Daimler bus division, visiting the new paint shop. One of the three Lutro spray booths can be seen in the background.

\section{ITW Gema becomes}

\section{Gema Switzerland GmbH}

$T^{\text {he }}$ he powder application system manufacturer ITW Gema is the new competence centre for electrostatic powder coating within the Graco Group. As part of its move from ITW to Graco, the international company has been renamed Gema

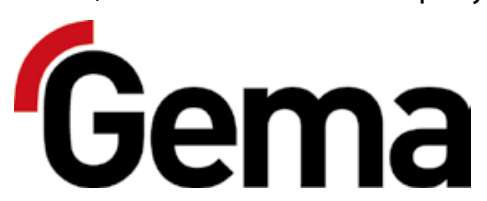

Switzerland $\mathrm{GmbH}$. At the same time, a new logo and a new corporate design will be introduced to give the Gema brand a fresh, modern image, while retaining links to Gema's traditional roots. The company's website (www. gemapowdercoat $\neg$ ing.com) has also been redesigned. Despite all these changes, the company's sales and dealer networks and its customer contacts will remain the same.

\section{Coventya Group takes over Molecular Technology}

$T^{n}$ he Coventya Group, a manufacturer of speciality chemicals for the electroplating and surface treatment industry, has acquired Molecular Technology Ltd., based in Wolverhampton in the UK. The company, which was founded in 1999, specialises in electrocoating products. These are currently sold in more than 20 countries and are mainly used for decorative applications. Coventya expects to benefit in particular from the company's expertise in processes for copper-nickel-chrome and precious metals, which will most importantly allow it to access new markets. In the next few weeks Molecular Technology will be renamed Coventya Ltd and, as a new Coventya Group site, will supply the complete Coventya product range on the British market.

\section{Award for Dürr Ecoclean}

In mid-June 2012, Dürr Ecoclean received a CMJ MachineBuilding and Metal-Working Award for the development of its EcoCBase W3 cleaning system. This award, which was presented for the first time in eight categories in 2012 by the China National Machine Tool Corporation in conjunction with the CMJ Chinamac Journal (a specialist technical periodical) and Adsale Publishing House, recognises innovative technologies and outstanding achievements in the fields of machine tool building and toolmaking. The powerful, cost-effective machine uses innovative processes to produce improved cleaning results and increased energy efficiency. The award ceremony took place on 13 June as part of Cimes, the China International Machine Tool \& Tools Exhibition, in Beijing.

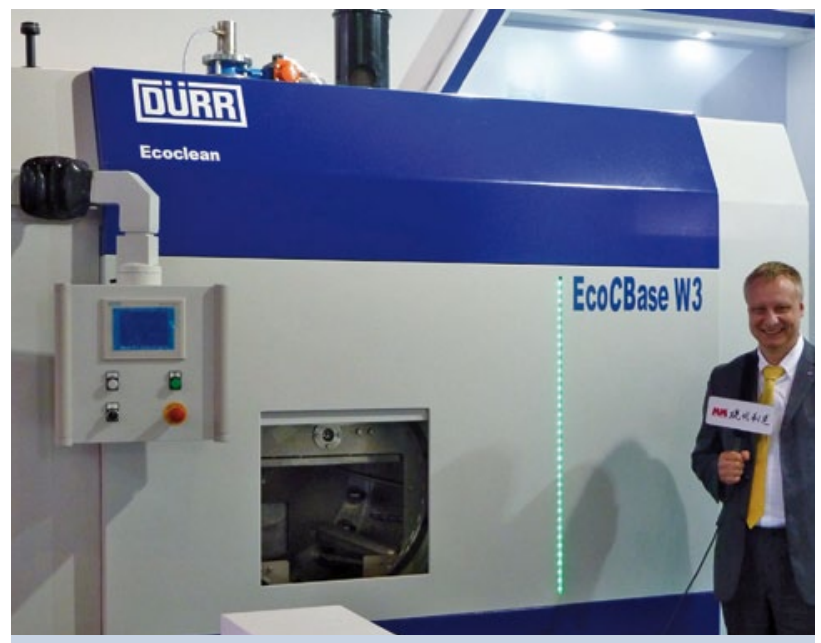

Markus Reissmann, head of Dürr-Ecoclean Shanghai, presents the award-winning cleaning machine at the Cimes trade fair in Beijing. 